\title{
Effect of Activation Temperature on Textural and Adsorptive Properties for Activated Carbon Derived from Local Reed Biomass: Removal of p-Nitrophenol
}

\author{
Nady A. Fathy, Sohair A. Sayed Ahmed and Reham M. M. Abo El-enin \\ Physical Chemistry Department, National Research Center, Egypt \\ crossref http://dx.doi.org/10.5755/j01.erem.59.1.961
}

(received in December, 2011, accepted in March, 2012)

\begin{abstract}
The use of the local common reed (CR) biomass as a novel precursor for activated carbon (AC) production was investigated. Three activated carbons were obtained by impregnation with 50 $\mathrm{v} / \mathrm{v} \% \mathrm{H}_{3} \mathrm{PO}_{4}$ under different activation temperatures at 400,450 and $500^{\circ} \mathrm{C}$ for $2 \mathrm{~h}$. Produced samples were characterized by scanning electron microscope (SEM), Fourier transform infrared spectroscopy (FTIR), and adsorption of $\mathrm{N}_{2}$ at $77 \mathrm{~K}$. The discharge of phenolic compounds into water-courses is a serious pollution problem which may affect the quality of water supply. Batch adsorption tests were carried out using para-nitrophenol (PNP) as a probe organic pollutant at the temperatures of 20,40 and $60^{\circ} \mathrm{C}$ to investigate the adsorption efficiency of developed carbons. Langmuir and Freundlich isotherm models were studied and the former model showed a satisfactory agreement with experimental data. Adsorption kinetic experiments were determined by pseudo-first order, pseudo-second order, and intraparticle diffusion models. The kinetic removal data of PNP agreed with the pseudo-second order and adsorption process controlled by film diffusion. Overall, the obtained results show that the activation temperature has a significant impact on textural and adsorption characteristics of developed ACs, producing an effective adsorbent for removal of organic pollutants from wastewater.
\end{abstract}

Keywords: Local common reeds, $\mathrm{H}_{3} \mathrm{PO}_{4}$ activation, porosity, adsorption of p-nitrophenol.

\section{Introduction}

Activated carbons (ACs) are of considerable interest to the adsorbent materials community, since they are initially developed as adsorbents to reduce the environmental pollution in water, soil, or air by separation and purification processes (Patrick 1995; Radovic et al. 2001). The adsorption capacity of AC depends not only on its surface area, but also on its internal pore structure, surface characteristic, and the presence of functional groups on the surface. These parameters depend on both the precursor used and the method of preparation. Therefore, an adequate characterization of the adsorbent is crucial to the adsorption and separation processes.
To reduce the cost of mass production, an inexpensive and local raw material with high carbon and low ash contents is preferred as precursor for preparing AC. In general, a number of feedstocks (lignocellulosics, polymers, solid wastes, etc.) may be used as precursors for the preparation of activated carbons. Two numerous routes are applied to prepare AC, for example: physical activation with steam, air and/or $\mathrm{CO}_{2}$ (Fan et al. 2004; Zhang et al. 2004; Lua et al. 2004), chemical activation with reagents such as $\mathrm{H}_{3} \mathrm{PO}_{4}, \mathrm{ZnCl}_{2}, \mathrm{KOH}, \mathrm{NaOH}$ (Rodriguez-Reinoso and Molina-Sabio 1992; Molina-Sabio et al. 1995; Ahmadroup and Do 1997; Jagtoyen and Derbyshire 1998; Girgis and El- Hendawy 2002; Girgis et al. 
2002; Fathy et al. 2010), or even combinations of physical and chemical activations (Molina-Sabio et al. 1996, El-Hendawy et al. 2001; Girgis et al. 2007). In treatment of various agricultural materials with $\mathrm{H}_{3} \mathrm{PO}_{4}$, the temperatures of $400-500^{\circ} \mathrm{C}$ were found suitable to obtain optimum textural properties of $\mathrm{AC}$ (Laine et al. 1989; Philip and Girgis 1996; Girgis and Ishak 1999, and others). Among the previous literature, the chosen phosphoric acid, as a dehydrating chemical activant, was widely used in production of AC.

Common reed (CR) biomass is widespread, dominant plant species in many aquatic ecosystems and is reported to contain a high amount of lignin and cellulose (Kufel and Kufel 1980). CR is abundant and widely spread grass in North Delta, Egypt, growing as an aggressive and invasive plant around lakes, ponds, river shores, and canals (Abdullah et al. 2010). Besides, it is useless material that has no economicvalue as foodstuff or animal feeding. Therefore, the use of $\mathrm{CR}$ as a precursor for ACs preparation could decrease its disposal and environmental concerns. However, few researchers have studied this novel plant biomass as biosorbent material for heavy metals removal (Southichak et al. 2006), or as activated carbon for removal of raw cane sugar (Abdullah et al. 2010) and dyes (Chen et al. 2010). They have found that CR (known as phragmites australis) can be used as a promising $\mathrm{AC}$ adsorbent in liquid phase applications. To the best of our knowledge, no research has been made on the use of $\mathrm{AC}$ from this precursor for studying the adsorption potential towards 4-nitrophenol as a common pollutant of phenolic compounds that is widely employed in pharmaceutical, petrochemical, and other chemical manufacturing processes.

Phenolic compounds are recognized carcinogens and are known to be toxic to the environment. Among many methods for removing these pollutants, activated carbon adsorption technique is still one of the most preferred methods, especially for effluents with moderate to low pollutant concentrations (Juang et al. 1999; Li et al. 2002; Moreno-Castilla 2004; Dabrowski et al. 2005). Moreover, activated carbon adsorption technique has been cited by the US Environmental Protection Agency as one of the best available environmental control technologies (BAT) (Derbyshire et al. 2001). Removal of phenolic compounds from aqueous solutions by various carbonaceous adsorbents has been studied in literature (Juang et al. 1996; Daifulla and Girgis 1998; Finqueneisel et al. 1998; Attia et al. 2003; Goyal 2004; Ayranci and Duman 2005; Namane et al. 2005; Mourao et al. 2006; Radhika and Palanivelu 2006; Tang et al. 2007; Anirudhan et al. 2009; Aravindhan et al. 2009).

The main objective of this study is to determine the effectiveness of AC produced from locally generated CR biomass on the removal of PNP from aqueous solution. Adsorption isotherms of Langmuir and Freundlich equations are often adopted to predict adsorption capacities. Besides kinetic models, pseudofirst order and pseudo-second order models as well as an intraparticle diffusion equation have been used to the kinetics of adsorption processes.

\section{Materials and methods}

\subsection{Preparation of activated carbons (ACs)}

The investigated lignocellulosic materials were obtained from hand-picked stems of local CR collected from around the Brolus Lake in North Delta, Egypt. The reed biomass was washed with boiling water and then air dried, cut into short pieces, and crushed to coarse grains. $20 \mathrm{~g}$ of the dried reed granules were soaked in $100 \mathrm{ml}$ of $50 \mathrm{v} / \mathrm{v} \% \mathrm{H}_{3} \mathrm{PO}_{4}$, left in contact overnight, and then separated by decantation. The impregnated CR was transported to a stainless steel tubular system admitted to a controller temperature. The soaked sample was firstly heated at $170^{\circ} \mathrm{C}$ at a rate of $10^{\circ} / \mathrm{min}$ and kept at this temperature for $30 \mathrm{~min}$ to remove water. Then the activation temperature was raised slowly to different temperatures of 400,450 , or $500^{\circ} \mathrm{C}$ with a heating rate of $10^{\circ} / \mathrm{min}$ under its own atmosphere. Pyrolysis was continued for $2 \mathrm{~h}$ at each temperature. After activation, the carbon produced was cooled down to an ambient temperature and then it was subjected to thorough washing with hot water until neutral $\mathrm{pH}$. Then the samples were dried overnight in an oven at $110^{\circ} \mathrm{C}$. The notation of activated carbons according to the activation temperatures (i.e. 400,450 , and $500^{\circ} \mathrm{C}$ ) was designated as follows: $A C 40, A C 45$, and $A C 50$, respectively. For example, a sample prepared by heating the $\mathrm{CR}$ at $400^{\circ} \mathrm{C}$ was labeled as $\mathrm{AC} 40$. Derived ACs were analyzed for carbon yield, ash content, and slurry pH (Table 1). For adsorption experiments, the samples were ground and sieved to 200 mesh particle sizes by standard sieves before storage and further testing. Finally, the ACs were then stored in tide (packed) bottles for later experimental use.

\subsection{Surface characteristics of the prepared ACs}

Surface features of common reed raw (CR), $A C 40$, and $A C 45$ were characterized by scanning electron microscopy (SEM-JEOL, JXA-840A Electron Probe Micro-Analyzer Japan). The oxygencontaining functional groups, presented in the $A C 45$ and their parent precursor, were characterized qualitatively by a Fourier transform infrared spectroscopy (FTIR - 6100 JASCO) in the range of $4000-400 \mathrm{~cm}^{-1}$. Also, the total acidic groups on AC were determined by Boehm titration method (Boehm 1994). $0.1 \mathrm{~g}$ of each powder AC mixed with $25 \mathrm{ml}$ of $0.1 \mathrm{~N} \mathrm{NaOH}$ in a glass bottle at a room temperature for $24 \mathrm{~h}$. $10 \mathrm{ml}$ of supernatant liquid from each bottle 
was titrated with $0.1 \mathrm{~N} \mathrm{HCl}$ standard solution. The differences in $\mathrm{HCl}$ consumed by blank and sample were the bases reacted with acidic groups on carbon surface, and the results were expressed as $\mathrm{H}^{+}$ equivalents per gram of carbon. The acidic surface groups such as phenolic, carboxylic, and lactone groups were neutralized by $\mathrm{NaOH}\left(p K_{a}=15.74\right)$. For phosphoric acid ACs from CRs, acidic groups also conclude some phosphorous-containing groups as evident by FTIR analysis.

\subsection{Porous properties of the developed activated carbons}

Porous properties of developed carbons were obtained from $\mathrm{N}_{2}$ adsorption at $77 \mathrm{~K}$ using a surface area analyzer (NOVA version 2.1, Quantachrome Corporation, USA). The specific surface area $\left(S_{B E T}\right.$, $\mathrm{m}^{2} / \mathrm{g}$ ) was calculated by applying the BET equation to the adsorption data $\left(P / P^{o}=0.05-0.35\right)$, and the total pore volume $\left(V_{t o t}, \mathrm{~cm}^{3} / \mathrm{g}\right)$ is currently obtained from the volume of nitrogen adsorbed at $P / P^{o}=0.95$. The average pore width $\left(D_{w}, \AA\right)$ was calculated from $\left(4 V_{\text {tot }} / S_{B E T}\right) \times 10^{4}$. Pore size distributions in the present samples were calculated using the Density Functional Theory (DFT), assuming slit pore. Also, $\mathrm{N}_{2}$ adsorption isotherms were analyzed by means of the $\alpha_{\mathrm{s}}$-method (Selles-Perez and Martin-Martinez 1991). By plotting the standard data of $\alpha_{\mathrm{s}}$-values against the adsorbed amount of $\mathrm{N}_{2}\left(V_{a}, \mathrm{~cm}^{3} / \mathrm{g}\right)$, three texture parameters could be obtained as follows: (1) the total surface area $\left(S^{\alpha}\right)$ from a slope of the first linear section connecting the adsorption points to the origin, (2) the non-microporous surface area $\left(S_{n}^{\alpha}\right)$ from a slope of the rectilinear section connecting the latter points (at $\alpha_{s} \geq 1.0$ ), and (3) the micropore volume $\left(V^{\alpha}{ }_{0}\right)$ from intersection of the latter line extrapolated to meet the $V_{a}$-axis (converted into $\mathrm{cm}^{3}$ of liquid nitrogen). Two other parameters are deduced microporous surface area $\left(S_{m i c}\right)=S^{\alpha}{ }_{t}-S^{\alpha}{ }_{n}$, and mesopore volume $\left(V_{\text {mes }}\right)=V_{\text {tot }}-V^{\alpha}{ }_{o}$.

\subsection{Adsorption measurements for p-nitrophenol (PNP)}

A batch procedure was applied to monitor the concentration of the adsorptive solution in contact with the adsorbent as a function of time. A stock solution of PNP $(1000 \mathrm{mg} / \mathrm{L})$ was prepared in distilled water and all working solutions were prepared by diluting the stock solution to the desired concentrations. Adsorption experiments were conducted at the temperatures of 20,40 and $60^{\circ} \mathrm{C}$ for $24 \mathrm{~h}$ to determine the maximum removal of PNP. The $\mathrm{pH}$ of aqueous solution was adjusted to 6 throughout adsorption tests in order to attain the maximum removal of PNP (Anirudhan et al. 2009).

In our experiments, a fixed amount $(0.2 \mathrm{~g})$ of activated carbon adsorbent and $100 \mathrm{ml}$ of a given concentration from PNP (40-300 mg/L) were added to a set of $250 \mathrm{ml}$ glass bottles, provided with screw-up tops. The filtered residual concentration of PNP was determined by the UV-Vis Spectrophotometer (Shimadzu PC2401) at $317 \mathrm{~nm}$. The amount of PNP taken by the obtained carbon sample was calculated by applying the mass-balance equation:

$$
Q_{e}=\frac{\left(C_{o}-C_{e}\right)}{\mathrm{m}} V
$$

where $Q_{e}$ is the amount of PNP adsorbed onto the activated carbon surface at equilibrium $(\mathrm{mg} / \mathrm{g}), C_{o}$ and $C_{e}$ are the liquid-phase initial and equilibrium concentrations of tested adsorbate put in contact with the adsorbent $(\mathrm{mg} / \mathrm{L})$, respectively; $V$ is the volume of PNP put in contact with the AC adsorbent $(\mathrm{ml})$ and $m$ is the mass of dry adsorbent in (mg).

\section{Results and discussion}

\subsection{General features for the prepared activated carbon adsorbents}

Three ACs are developed here under mild condition of phosphoric acid concentration of $50 \mathrm{v} / \mathrm{v}$ $\%$ and at heat treatment temperatures of $400-500^{\circ} \mathrm{C}$ (HTT). The process seems feasible, as previously treated with other plant by-products in the literature. It is observed that the carbon yield of samples decreases from 45 to $41.7 \%$ as the reaction temperature increases while ash content increases from $6.72-9.32$ $\%$ (Table 1).

Table 1. Some physico-chemical measurements of the prepared activated carbons

\begin{tabular}{||c|c|c|c|c||}
\hline \multirow{2}{*}{$\begin{array}{c}\text { Sample } \\
\text { symbol }\end{array}$} & \multicolumn{4}{|c||}{ Physico-chemical measurements } \\
\cline { 2 - 5 } & $\begin{array}{c}\text { Carbon } \\
\text { yield (\%) }\end{array}$ & $\begin{array}{c}\text { Slurry } \\
\text { pH }\end{array}$ & $\begin{array}{c}\text { Ash } \\
\text { content } \\
\text { (\%) }\end{array}$ & $\begin{array}{c}\text { Total acidity } \\
\text { (H'mmol/g) }\end{array}$ \\
\hline AC40 & 45 & 4.40 & 6.72 & 2.41 \\
\hline AC45 & 43.5 & 3.82 & 8.52 & 2.45 \\
\hline AC50 & 41.7 & 3.62 & 9.32 & 2.69 \\
\hline \hline
\end{tabular}

This is expected that the increase in temperature will release volatiles, thereby leading to a decrease in yield. This finding was also reported by Lua and Ting (2004). On the other hand, the ash content in the inherited parent CR plant was found to be $\sim 4.44 \%$, which is also the same result as reported by Abdullah et al. (2010). An increase in ash content may be ascribed to the additional inorganic minerals accumulated through dehydration of the phosphoric acid in the form of phosphate products, such as polyphosphates with organic and inorganic phosphates (Puziy et al. 2002 and 2007). These are permeated in the intricate porosity and some of them can not be easily leached in the washing process (Abdullah et al. 2010). These components might explain the observed acidity character of these $\mathrm{H}_{3} \mathrm{PO}_{4}-$ 
activated carbons which are evident by slurry $\mathrm{pH}$ (3.62-4.4), and total acidity $\left(2.41-2.69 \mathrm{mmol} \mathrm{H}^{+} / \mathrm{g}\right.$ carbon). Also, this result was recently postulated on ACs prepared from activation of fruit stones or polymers with $\mathrm{H}_{3} \mathrm{PO}_{4}$ (Puziy et al. 2002 and 2007) and is similar to those obtained by Abdullah et al. (2010).

\subsection{Investigation of morphology and surface functional groups}

SEM micrographs of the raw materials and their ACs prepared by activation with $50 \mathrm{v} / \mathrm{v} \% \mathrm{H}_{3} \mathrm{PO}_{4}$ at 400 and $450^{\circ} \mathrm{C}$ are shown in Figure 1 . These images indicate that activation of $\mathrm{CR}$ with moderate concentration phosphoric acid at low temperatures affects significantly its surface structure on a microscopic scale $(20 \mu \mathrm{m}$, magnification 2000x). According to the micrograph, the cavities on the surfaces have resulted from the evaporation of the activating agent during carbonization, leaving the space previously occupied by the activating agent. This conclusion shows that the increase in a pyrolysis temperature produces a dramatic change on the cellular structure accompanied by generation of large pores of different shapes and sizes (micro-, meso- or macropores). The activation process is being accompanied by the evolution of gases and liquids of low molecular weight resulting from decomposition processes. A comparison of the SEM images of CR and the prepared ACs (Fig. 1) illustrates that phosphoric acid activation has generated a welldeveloped porous structure.
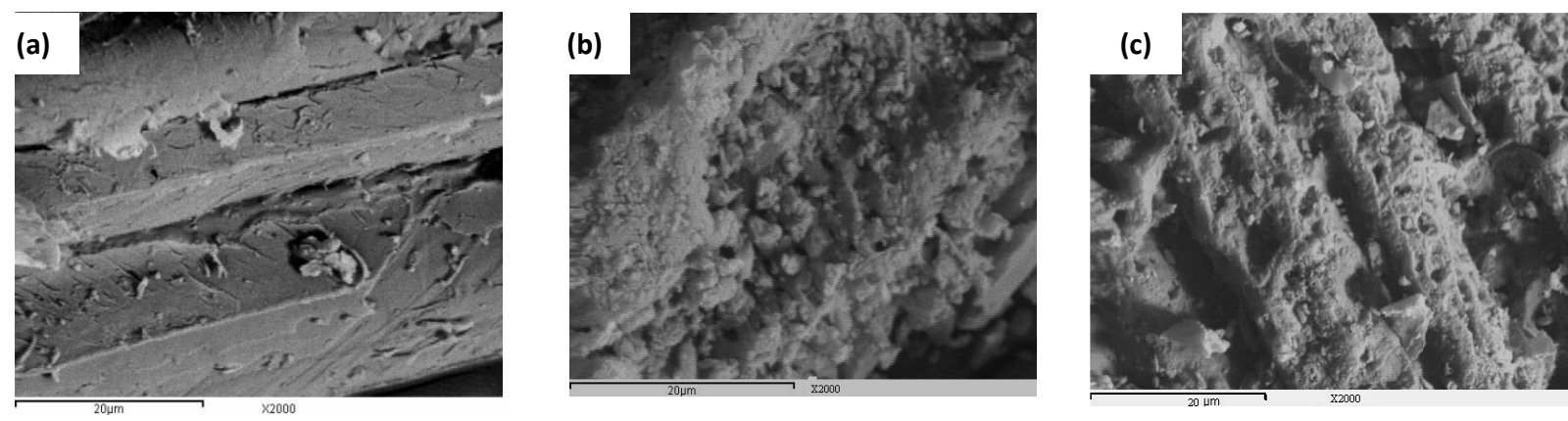

Fig. 1. SEM images of (a) CR-raw (b) AC40 and (c) AC45 samples

Table 2.

FTIR absorption bands CR-raw and AC45 sample

\begin{tabular}{|c|c|}
\hline CR-raw & AC45 \\
\hline Absorption bands $\left(\mathbf{c m}^{-1}\right)$ & Absorption bands $\left.\mathbf{c m}^{-1}\right)$ \\
\hline 3404 (broad) & 3423 (broad) \\
\hline 2922 (shoulder) & 2950 and 2880 (shoulders) \\
\hline $1740,1600-1638$ (shoulders) & 1627,1560 and 1510 (shoulders) \\
\hline 1510 (shoulder) & 1324 and 1269 (shoulders) \\
\hline 1060 (very sharp) & 1020 (sharp) \\
\hline $980-600$ (shoulders) & $900-734$ (shoulders) \\
\hline
\end{tabular}

Table 2 summarizes the principal absorption bands which demonstrate the presence of oxygen functional groups in virgin CRs and AC45 sample prepared at $450^{\circ} \mathrm{C}$. Reed biomass belongs to lignocellulosic materials which consist of mainly cellulose and lignin components enriching by carbon, hydrogen, and oxygen elements in their inherent structure. By analyzing their FTIR spectra ( $c f$. Table 2 ), some characteristic absorption peaks were found. A broad peak at around 3404 or $3423 \mathrm{~cm}^{-1}$ is usually ascribed to vibration of $\mathrm{H}$-bonded $-\mathrm{OH}$ groups. Two shoulder bands located around 2950 and $2880 \mathrm{~cm}^{-1}$ are caused by $\mathrm{C}-\mathrm{H}$ symmetric and asymmetric stretching of residual methylene groups on the surface. The peak at $1620 \mathrm{~cm}^{-1}$ corresponds to the $\mathrm{C}=\mathrm{C}$ stretching, that may be attributed to the lignin aromatic $\mathrm{C}-\mathrm{C}$ bond (Villaescusa et al. 2004) and the peak at $1510 \mathrm{~cm}^{-1}$ is assigned to lignin esters (Devarly et al. 2008). The band around $1700 \mathrm{~cm}^{-1}$ can be ascribed to the vibration of $\mathrm{C}=\mathrm{O}$ bond in carboxylic acids, ketones, aldehydes, lactones, or esters. The intensity of absorption bands around $1300-1000 \mathrm{~cm}^{-1}$ indicates the existence of a $\mathrm{C}-\mathrm{O}$ single bond in carboxylic acids, alcohols, phenols, and esters, or a $\mathrm{P}=\mathrm{O}$ bond in phosphate esters, an $\mathrm{O}-\mathrm{C}$ bond in $\mathrm{P}-\mathrm{O}-$ $\mathrm{C}$ linkage and $\mathrm{P}=\mathrm{OOH}$ bond (Puizy et al. 2002 and 2007). The stretching vibrations of $\mathrm{P}-\mathrm{O}-\mathrm{P}$ in polyphosphate, or the ionized linkage $\mathrm{P}^{+}-\mathrm{O}^{-}$in acid phosphate esters lead to the appearance of the weak peak around $1050 \mathrm{~cm}^{-1}$ (Guo and Rockstraw 2007). This suggests the presence of phosphorous-containing groups in this carbon. The relative intensity of the band at $1060 \mathrm{~cm}^{-1}$ was decreased and shifted to 1020 $\mathrm{cm}^{-1}$ in FTIR spectrum of AC45 sample characterizing $\mathrm{C}-\mathrm{O}$ single bond in carboxylic acids, alcohols, or ethers. Shoulder peaks appearing between 
900 and $600 \mathrm{~cm}^{-1}$ were assigned to an out-of-plane $\mathrm{C}$ $\mathrm{H}$ bending mode in aromatic rings. Overall, FTIR results have revealed the existence of carbonylcontaining carboxylic, lactone, and phenolic groups, and phosphorous-containing groups in the prepared carbon, which have enhanced the adsorptive properties.

\subsection{Porosity development in relation to the change in the activation temperature}

The activation temperature is one of the most important factors affecting the development of porosity in ACs. The $\mathrm{N}_{2}$ adsorption-desorption isotherms of $\mathrm{ACs}$ prepared with $\mathrm{H}_{3} \mathrm{PO}_{4}$ at low activation temperatures of $400-500^{\circ} \mathrm{C}$ for $2 \mathrm{~h}$ are shown in Figure 2. Porous textures evaluated from $\mathrm{N}_{2}$ adsorption isotherms are given in Table 3. In fact, nitrogen adsorption isotherm gives approximate assessment of the pore size distributions. Clearly, it is seen that the adsorption isotherm of the AC prepared at $400^{\circ} \mathrm{C}$ (AC40) represents Type $I$ in the BDDT classification, which is a characteristic of typical microporous solid with a well-developed microporosity. This obviously shows that porosity of the AC40 obtained from CR impregnated with $50 \%$ $\mathrm{H}_{3} \mathrm{PO}_{4}$ was initiated with the development of micropores, mostly ultra- and super-micropores. While ACs prepared at $400^{\circ} \mathrm{C}$ and $450^{\circ} \mathrm{C}$ have increments in terms of the micropore surface area, micropore volume and total volume. Thus, the increase in a heating temperature enhanced the development of micropores and total volume because of a possibility of generating new micropores and mesopores in the carbon. When the activation temperature was increased to $500^{\circ} \mathrm{C}$ (AC50), a larger total volume and mesopore volume are observed as compared to $\mathrm{AC}$ prepared at $400^{\circ} \mathrm{C}$ (Table 3 ).

Table 3.

Textural properties of the obtained activated carbons

\begin{tabular}{|c|c|c|c|c|c|c|c|c|c|c|}
\hline $\begin{array}{c}\text { Sample } \\
\text { Notation }\end{array}$ & $\begin{array}{c}S_{B E T} \\
\left(m^{2} / g\right)\end{array}$ & $\begin{array}{c}V_{t o t} \\
\left(\mathrm{~cm}^{3} / \mathrm{g}\right)\end{array}$ & $\begin{array}{l}D_{w} \\
(A) \\
\end{array}$ & $\begin{array}{c}S_{t}^{a} \\
\left(m^{2} / g\right)\end{array}$ & $\begin{array}{c}S_{n}{ }^{a} \\
\left(m^{2} / g\right)\end{array}$ & $\begin{array}{c}S_{m i c} \\
\left(m^{2} / g\right)\end{array}$ & $\begin{array}{c}V_{o}^{a} \\
\left(\mathrm{~cm}^{3} / \mathrm{g}\right)\end{array}$ & $\begin{array}{c}V_{\text {meso }} \\
\left(\mathrm{cm}^{3} / \mathrm{g}\right)\end{array}$ & $\begin{array}{c}\boldsymbol{S}_{\text {mid }} \boldsymbol{S}_{\boldsymbol{t}}{ }^{\alpha} \\
(\%)\end{array}$ & $\begin{array}{c}V_{o}^{a} / V_{\text {tot }} \\
\text { (\%) }\end{array}$ \\
\hline $\mathrm{AC40}$ & 164 & 0.1299 & 31.7 & 174.5 & 87 & 87.5 & 0.0556 & 0.0743 & 50.1 & 42.8 \\
\hline AC45 & 318 & 0.3370 & 42.4 & 325 & 45 & 280 & 0.0464 & 0.2906 & 86.2 & 13.7 \\
\hline AC50 & 299 & 0.3560 & 47.6 & 305 & 241 & 64 & 0.0247 & 0.3313 & 20.9 & 6.94 \\
\hline
\end{tabular}

Activation at $450^{\circ} \mathrm{C}$ brings not only a considerable increase in the amount of pore volumes $\sim 159 \%$ ( $V_{\text {tot }}$ increases from 0.1299 to $0.3370 \mathrm{~cm}^{3} / \mathrm{g}$ ) but also in the nature of the pores developed (i.e. $\sim 55.6 \%$ of micropore volume is lost between 400 and $40^{\circ} \mathrm{C}$ while mesopore volume increases about $\sim 345$ $\%$ ). At above $400^{\circ} \mathrm{C}$, the $\mathrm{N}_{2}$ adsorption-desorption isotherms display Type $I$ with hysteresis loops referring to widening micropores or generation of mesopores as the temperature is increased. These hysteresis loops are typical of slit-shaped pores and wide distribution of pore sizes (Rouquerol et al. 1999). Moreover, the widening in the knee of isotherms indicates the presence of large micropores and mesopores. The shape of an adsorption isotherm may give the qualitative information on both adsorption capacity and the extent of the surface area available to the adsorbate. Larger hysteresis loop observed in AC50 sample suggests a notable contribution of higher mesopores to their porous structure. This is supported by the average pore width ( $D_{w}$ increases from 31.7 to $47.6 \AA$ ), which is classified as mesopores carbon $\left(D_{w}>20 \AA\right.$ or $\left.2 \mathrm{~nm}\right)$. The presence of mesopores together with micropores in the activated carbon enhances their adsorption capacities, especially for larger molecules adsorbates (Chandra et al. 2007).

For AC50 sample, a remarkable reduction in the total surface area as compared to AC45 sample, which amounted to $6.5 \%\left(\mathrm{~S}_{\mathrm{t}}^{\alpha}\right.$ decreases from 325 to 305 $\left.\mathrm{m}^{2} / \mathrm{g}\right)$, and microporosity $\left(\mathrm{S}_{\mathrm{mic}} / \mathrm{S}_{\mathrm{t}}{ }^{\alpha}\right.$ decreases from 86.2 to $20.9 \%$ ), was accompanied by an increase in mesoporosity indicating pore widening of the micropores and creation of new pores. This observation revealed that an increase in activation temperature from 450 to $500^{\circ} \mathrm{C}$ caused some of the pores to become larger or even collapse, thus contributed to the reduction in the surface area (Diao et al. 2001). Thereof, microporosity of activated carbon decreases with an increase in the temperature from 450 up to $500^{\circ} \mathrm{C}$. Therefore, the activation temperature of $450^{\circ} \mathrm{C}$ exhibits good porous texture parameters. It can be concluded that this is the optimum activation temperature to the $\mathrm{CR}$ biomass. Other authors agree that $450^{\circ} \mathrm{C}$ is the optimum temperature for porosity development in carbons prepared by phosphoric acid activation of different precursors (Molina-Sabio et al. 1995; Philip and Girgis 1996; Girgis and Ishak 1999). Also, the surface area and micropore volume depend on the temperature according to the type of carbonaceous precursors, i.e., the maximum surface area was observed at $450^{\circ} \mathrm{C}$ for coconut shells (Laine et al. 1989) and apple pulp (Suarez-Garcia et al. 2002), $350-500^{\circ} \mathrm{C}$ for white oak (Jagtoyen and Derbyshire 1998 ), and $500^{\circ} \mathrm{C}$ for bituminous coal (Jagtoyen et al. 1992). This difference in the optimum activation temperature has been accredited to reactivity of the chemical structure in lignocellulosic materials, coals, and others (Puziy et al. 2002). 

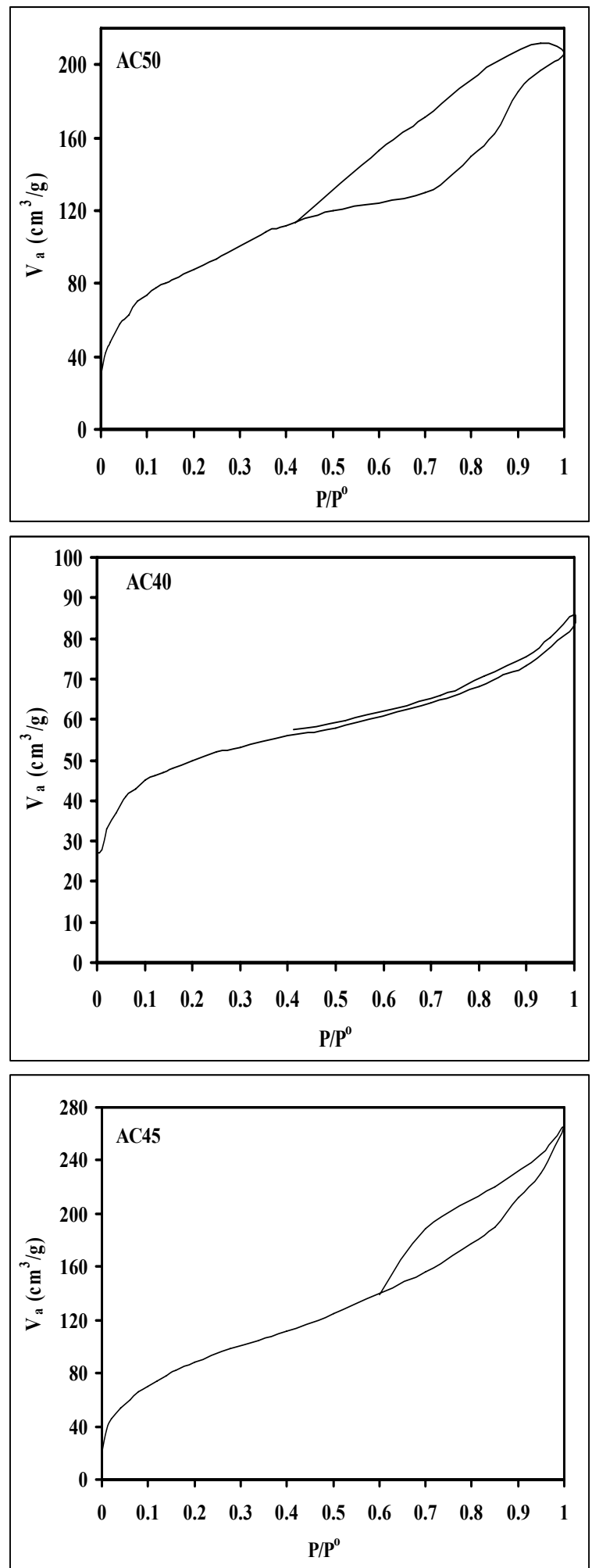

Fig. 2.

$\mathrm{N}_{2}$ adsorption isotherms of the prepared activated carbons

The reaction mechanism of $\mathrm{H}_{3} \mathrm{PO}_{4}$ was postulated earlier by Jagtoyen et al. (1992), and they have reported that $\mathrm{H}_{3} \mathrm{PO}_{4}$ acts in two different ways during the chemical activation of lignocellulosic feedstocks: (i) promoting the rupture of bonds in the biopolymer constituents, and (ii) forming cross-links through cyclization and condensation processes. In addition, $\mathrm{H}_{3} \mathrm{PO}_{4}$ combines with organic species forming phosphate and polyphosphate bridges that connect biopolymer fragments; thereby partially hindering the contraction in materials when the temperature increases. These bridges become thermally unstable above $450^{\circ} \mathrm{C}$, thus their loss produces a contraction in the material, which will result in a decrease in porosity.

Basically, the structure of ACs containing pores is classified according to the International Union of Pure and Applied Chemistry (IUPAC) into three groups: micropores (pore size $<20 \AA$ ), mesopores (20-500 $\AA$ ), and macropores (> $500 \AA)$. The pore size distributions (PSDs) of the hereby ACs evaluated by applying the DFT method on $\mathrm{N}_{2}$ adsorption data are shown in Figure 3. For AC45 and AC50 samples, the pore size distributions are mostly similar to each other indicating that the porous structure can be already formed at a temperature as low as $400^{\circ} \mathrm{C}$. The distributions of pore size in the prepared carbons are found to be: $4.17,19.3$ and $26.4 \AA$ for AC40; 17.6, 26.4, 33.1 and $43.6 \AA$ for AC45 and 16.8, 28.9 and 55 $\AA$ for AC50. It is obvious that the AC40 and AC50 represent three distinct pore sizes, while AC45 shows four distinct pore sizes between 10 and $50 \AA$ indicating that the prepared carbon at $450^{\circ} \mathrm{C}$ has a typical micro-mesoporous structure. When the temperature is raised to $450^{\circ} \mathrm{C}$, the main peak at 4.17 $\AA$ for AC40 is shifted to a broad peak at $17.6 \AA$ for AC45 meaning that the rise in temperature widens the micropores (ultra- $<7 \AA$ or super- $>7 \AA$ ) on the AC40 surface. When the temperature is increased to $500^{\circ} \mathrm{C}$, disappearance of peaks at $26.4,33.1$ and 43.6 $\AA$ for AC45 and creation of two small broad peaks at 28.9 and $55 \AA$ are observed. This is probably due to volatilization of some chemical structures composing some pore walls, which are not resistant to high temperatures. Comparing the PSDs of these samples, it is shown that there is a reduction in the highest peak between 25 and $30 \AA$ when the temperature is increased to $500^{\circ} \mathrm{C}$, which may be attributed to the shrinkage effect. Overall, the activated carbons here contain pore sizes in the mesoporosity region (20-55 $\AA$, closing to the lower limit of mesoporosity). This behavior could be a promise that the prepared carbons are effective adsorbents for removal of paranitrophenol pollutants from wastewater.

\subsection{Equilibrium adsorption of PNP onto the prepared ACs}

Para-nitrophenol (PNP) was selected as a model pollutant to evaluate the adsorption capacity of prepared activated carbons using batch mode. Adsorption of PNP was recommended long time ago (Giles and Trivedi 1969) for the determination of specific surface area, and it has been extensively reported in recent years (Finqueneisel et al. 1998; Nouri et al. 2002; Goyal 2004; Tang et al. 2007; Ahmaruzzaman and Gayatri 2010). Moreover, it is a 
polar organic pollutant having the specific cross sectional area (or the area covered by an adsorbed molecule) of $52 \AA^{2}$ established by Giles and Trivedi (1969).

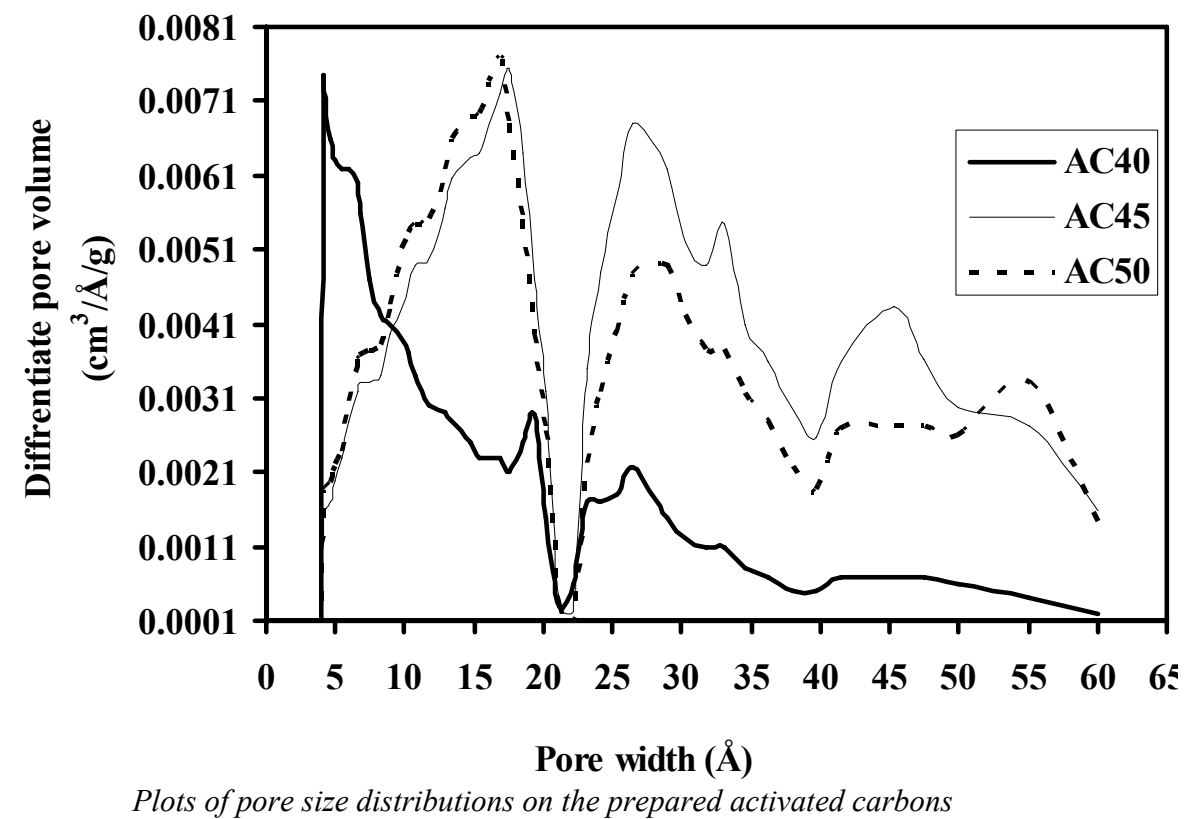

Fig. 3.

Plots of pore size distributions on the prepared activated carbons

The surface acidity of obtained activated carbons might affect the $\mathrm{pH}$ of the solution for the adsorption of PNP onto the activated carbons. Table 1 shows the surface acidic groups of ACs. The total acidity of $\mathrm{AC} 40$ was the lowest, whereas it was found to be the highest in the case of AC50. The total or external surface charges on the surface of carbon are positive at a lower solution of $\mathrm{pH}$. The maximum adsorption of PNP was obtained at $\mathrm{pH} 6$ as found previously by Anirudhan et al. 2009. Pura and Atun (2005) reported that PNP adsorbate was dissociated to an anionic component and $\mathrm{H}^{+}$ions in aqueous solution in the $\mathrm{pH}$ range of 4.96-6.0. Accordingly, the adsorption of PNP occurs by electrostatic attraction between the negatively charged phenoxide group $\left(\mathrm{C}_{6} \mathrm{H}_{4} \mathrm{O}_{3} \mathrm{~N}\right)^{-}$and the positively charged on carbon surface. It is to be taken into consideration that the $\pi$-electron clouds of the benzene ring are delocalized over the aromatic ring of PNP leading to strong $\pi-\pi$ interactions between the carbon surface and PNP molecules. Among the earlier studies on adsorption of PNP and other phenolic compounds on activated carbons, the adsorption capacity was dependant upon several factors such as: (i) surface area and pore volume of carbon as well as bonded carbon-oxygen groups on the surface (acidic or basic), (ii) solubility, molecular dimensions, or molecular weight of organic compounds, and hydrophobicity of a substituent, and (iii) electron donor-acceptor complexes formed between the basic sites on the carbon surface and the aromatic ring of the phenols.

The adsorption isotherm data evaluated from the batch experiments, which are carried out on removal of PNP onto ACs, are shown in Figure 4. It was clearly observed that the adsorption isotherms of PNP as a function of the adsorption temperatures of 20,40, and $60^{\circ} \mathrm{C}$ correspond to the isotherms of Type I, i.e. the convex upward curves meaning a strong adsorption (Brunauer et al. 1938). Also, when the temperature increased from 20 to $40^{\circ} \mathrm{C}$ (Fig. 4), the adsorption capacity was increased and then decreased as the temperature increases to $60^{\circ} \mathrm{C}$. The increased adsorption capacity with the raising in temperature is attributed to the acceleration of slow adsorption steps or the creation of some active sites on the adsorbent surface (Hashem 2007). Additional suggestions have been reported by Horsfall and Spiff (2005), who have proposed that is due to weak interaction between adsorbate and adsorbent at the point of which physisorption dominates. On the other hand, increase in adsorption capacity at the increased adsorption temperature can be also ascribed to the enhancement in mobility of an adsorbate from the bulk solution. Opposite behavior was observed when temperature increased from 40 to $60^{\circ} \mathrm{C}$ and also demonstrated by Chang et al. (2009). They have found that the uptake of p-nitrophenol onto the anion-cation modified palygorskite increased with an increase in the temperature from 20 to $40^{\circ} \mathrm{C}$ and decreased when the temperature rose from 40 to $60^{\circ} \mathrm{C}$. Therefore, the maximum uptake of PNP by these carbon adsorbents occurred at $40^{\circ} \mathrm{C}$.

Two familiar adsorption isotherm models are performed in this study, i.e. Langmuir and Freundlich equations in order to determine the equilibrium adsorption isotherm which is important in evaluating the adsorption capacity of p-nitrophenol by the studied carbon adsorbents.

Langmuir equation is based on a theoretical model and assumes that the maximum adsorption corresponds to a monolayer saturated with adsorbate molecules on the adsorbent surface that is energetically homogeneous. The equation is given as: 
$Q_{e}=K_{L} q_{m} C_{e} /\left(1+K_{L} C_{e}\right)$

Langmuir parameters can be easily obtained from its linearized form:

$\frac{C_{e}}{Q_{e}}=\frac{1}{K_{L} q_{m}}+\frac{C_{e}}{q_{m}}$

where $K_{L}(\mathrm{~L} / \mathrm{mg})$ is a parameter which refers to the adsorption energy $\left(K_{L} \alpha \mathrm{e}^{-\Delta \mathrm{G} / \mathrm{RT}}\right) ; q_{m}(\mathrm{mg} / \mathrm{g})$ is a constant relative to the maximum monolayer adsorption capacity. The values of $K_{L}$ and $q_{m}$ are presented in Table 4.

On the other hand, Freundlich equation is an empirical model that considers heterogeneous adsorptive energies on the adsorbent surface and is expressed as follows:

$$
q_{e}=K_{F} C_{e}^{1 / n}
$$

where $K_{F}\left(\mathrm{mg} / \mathrm{g}(\mathrm{L} / \mathrm{mg})^{1 / \mathrm{n}}\right)$ is relative to the adsorption capacity and $1 / n$ refers to the process intensity. The magnitude of the exponent $n$ gives an indication of favorability of the adsorbent/adsorbate system. The value of $1 / n>1$ signifies that solute has low affinity to the adsorbent at low concentrations and an isotherm curve shows a concave profile which corresponds to S-type. The value of $1 / n=1$ corresponds a C-type isotherm curve which is strictly linear. Likewise, the value of $1 / n<1$ is an indication of favorable adsorption and is classified to L-type isotherm (cf. Table 4). This isotherm reflects a relatively high affinity between the solute and the solid phase. A linear form of equation (4) can be written as:

$\ln Q_{e}=\ln K_{F}+1 / \mathrm{n} \ln C_{e}$

The coefficients of determination of the data suitable to each of the above models are presented in Table 4 together with the value of the characteristic parameters for each of the two models studied. According to the regression coefficient $\left(R^{2}\right)$, Langmuir isotherm model provided good suitability for the adsorption of PNP molecules over the obtained ACs with $R^{2}=0.976-0.999$. Also, the adsorption efficiency of the prepared carbons towards PNP removal was ranked in the order: $\mathrm{AC} 45$ $>$ AC50 $>$ AC40 according to the calculated values of $q_{m}$ at each temperature of adsorption (e.g., at $20^{\circ} \mathrm{C}, q_{m}$ $=212.7 \mathrm{mg} / \mathrm{g}$ for $\mathrm{AC} 45,137 \mathrm{mg} / \mathrm{g}$ for AC50 and $116.3 \mathrm{mg} / \mathrm{g}$ for AC40, respectively). This behavior can be attributed to the effect of internal porosity (surface area and pore volume) of these carbons which is followed by the same sequence order.

Additionally, a characteristic of Langmuir isotherm is the definition of dimensionless factor $R_{L}=$ $1 /\left(1+K_{L} C_{o}\right)$ called a separation factor (Ayranci and Duman 2005). The adsorption process is considered favorable, when the values of this factor are between $0<R_{L}<1$, which are obtained in all cases of PNP adsorption studied (Table 4).
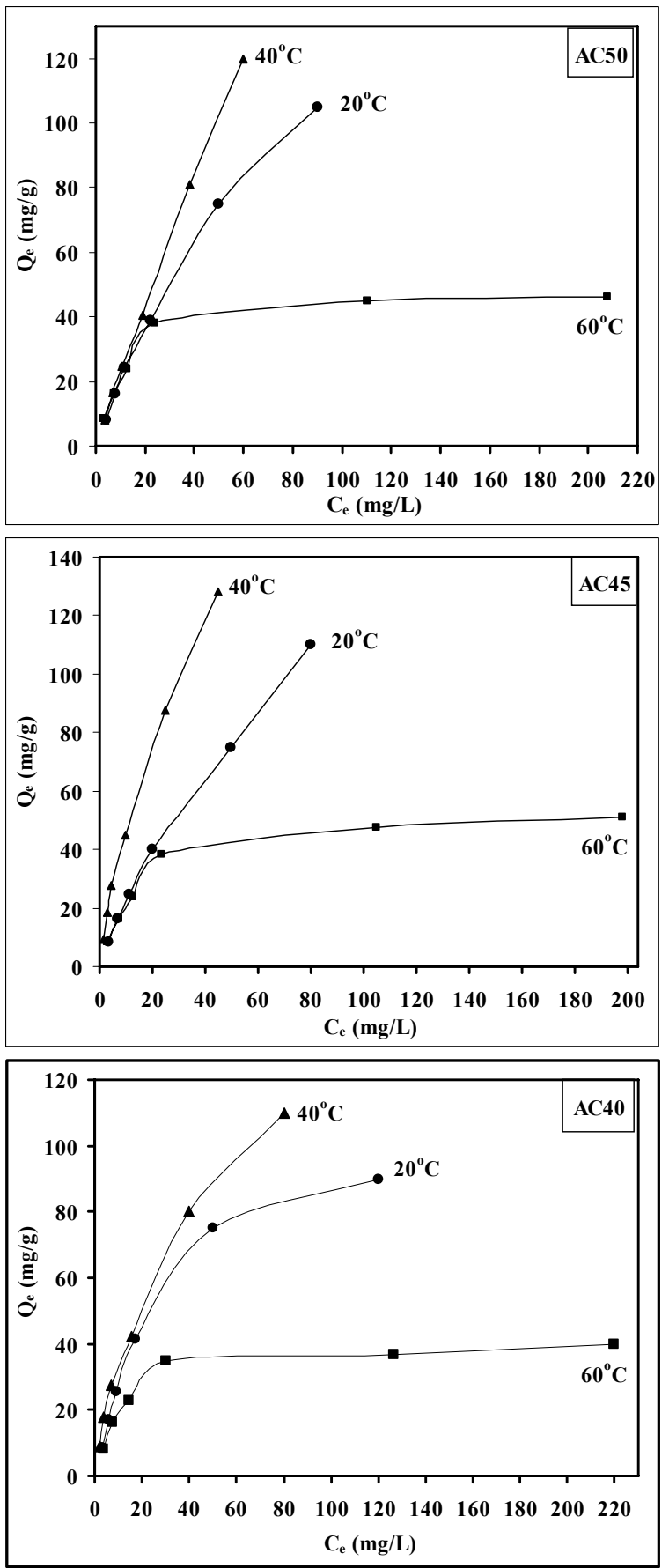

Fig. 4. Adsorption isotherms of p-nitrophenol onto ACs at 20,40 and $60^{\circ} \mathrm{C}$

The observed differences in carbon texture should impact on the adsorption process of PNP onto the prepared carbons. Earlier investigations presented in literature (Attia et al. 2003; DeryloMarczewska et al. 2004) suggest a higher selectivity of adsorption in respect to preferable adsorbent material containing narrow micro- or mesopores. Figure 5 shows the correlation diagram between monolayer capacity $\left(q_{m}, \mathrm{mg} / \mathrm{g}\right)$ 
and specific surface area $\left(S_{B E T}, \mathrm{~m}^{2} / \mathrm{g}\right)$ of the obtained carbons. It can be seen that an increase in the surface area results in an increase in adsorption capacity. Also it is shown that the adsorption of PNP on these samples is correlated with an increase in the total pore volume $\left(V_{t o t}\right.$, $\left.\mathrm{cm}^{3} / \mathrm{g}\right)$ and microporosity $\left(S_{\text {mic }} / S_{t}^{\alpha}, \%\right)$ as given in Table 3.

Table 4.

Langmuir, Freundlich, and thermodynamic parameters for adsorption of PNP onto the ACs

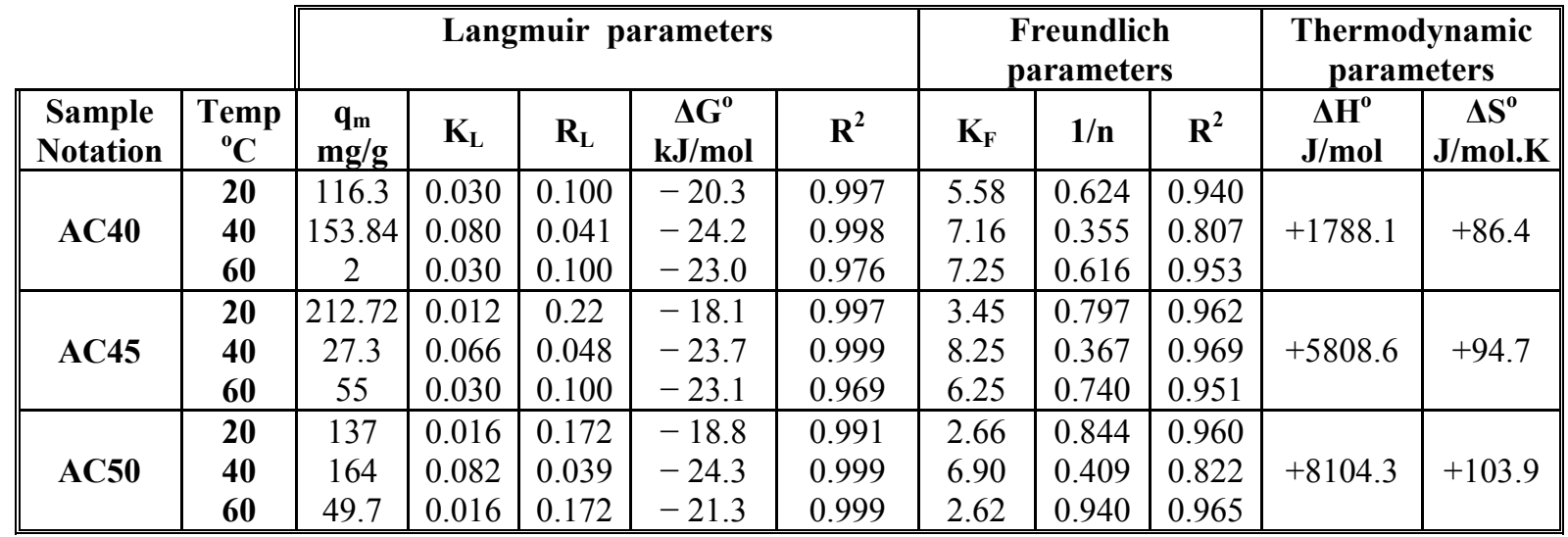

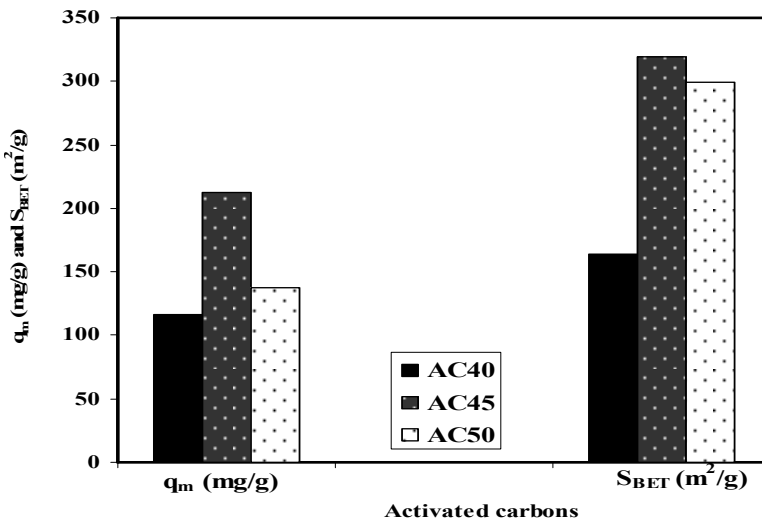

Fig. 5. Correlation diagram between monolayer capacity $\left(q_{m}, m g / g\right)$ and specific surface area $\left(S_{B E T}, \mathrm{~m}^{2} / g\right)$ of the obtained carbons at $20^{\circ} \mathrm{C}$

\subsection{Kinetic studies on the removal of PNP by the prepared carbons}

Adsorption kinetics describes the rate of PNP uptake on ACs and this rate controls the equation time. Figure 6 shows the effect of contact time on the percent removal of PNP at constant initial concentration of $200 \mathrm{mg} / \mathrm{L}$ and the temperature of $20^{\circ} \mathrm{C}$. It has been observed that the percent removal of PNP is increased from 31 to 64,43 to 66 and 49 to 75 $\%$ onto AC40, AC45 and AC50, respectively, within $140 \mathrm{~min}$ of an experiment. The optimum equilibrium time was attained at $60 \mathrm{~min}$, which is considered the best contact time as compared to other previous studies of reported $4 \mathrm{~h}$ for adsorption of PNP onto activated jute stick char (Ahmaruzzaman and Gayatri 2010). Also, the same equilibrium time was attained for adsorption of p-nitrophenol by anion-cation modified palygorskite (Chang et al. 2009).

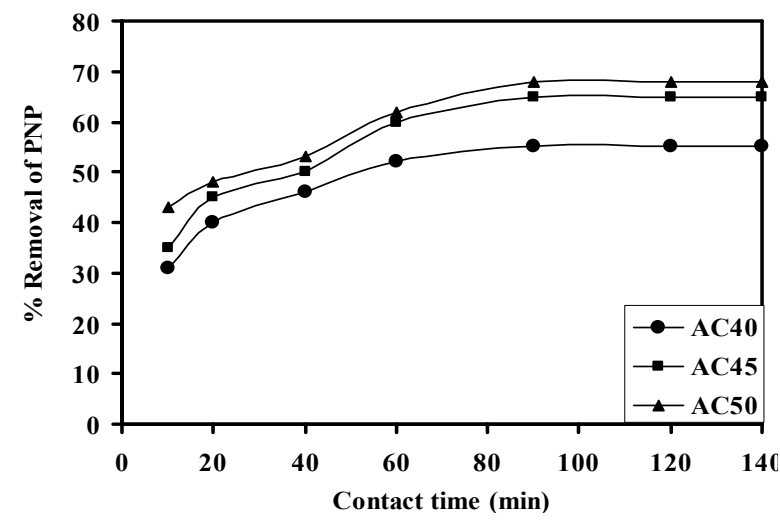

Fig. 6. Effect of contact time on the removal of PNP onto ACs $\left(C_{o}=200 \mathrm{mg} / \mathrm{L}\right.$, temperature $=20^{\circ} \mathrm{C}$, volume $=100 \mathrm{ml}$, contact time $=2 \mathrm{~h}$ and carbon dose $=$ $0.2 \mathrm{~g})$

Kinetic removal of para-nitrophenol by these carbons has been analyzed by pseudo-first order and pseudo-second order kinetic models at $200 \mathrm{mg} / \mathrm{L}$ initial concentration of PNP. Their kinetic parameters are provided in Table 5 and have been compared as based on the correlation coefficients $\left(R^{2}\right)$.

The rate constant of adsorption is determined from the following pseudo-first order rate expression obtained from Lagergren equation (Lagergren 1898):

$\log \left(q_{e}-q_{t}\right)=\frac{\log q_{e}-k_{1} t}{2.303}$

where $q_{t}$ is the amount of PNP adsorbed at time $t$ (min); $k_{1}$ is the pseudo-first order rate constant of adsorption. A straight line of $\log \left(q_{e}-q_{t}\right)$ vs. $t$ plots was observed for adsorption of PNP onto the studied ACs (not shown here), which suggests the applicability of this kinetic model. The $k_{l}$ and $q_{e}$ values were determined from the slope and intercept of this plot at different contact time. 
The kinetics of adsorption can also be described by a pseudo-second order model and is given by the equation (Ho and McKay 1999):

$$
\frac{t}{q_{t}}=\frac{1}{k_{2} q_{e}{ }^{2}}+\frac{t}{q_{e}}
$$

The second order rate constant, $k_{2}$ and $q_{e}$ values were evaluated from the slope and intercept of the plots obtained by plotting $t / q_{t} v s$. $t$ ( $\mathrm{min}$ ) (not shown here). The correlation coefficients $\left(R^{2}\right)$ for the first- order kinetic model were determined and compared to that of the second-order kinetic model. It can be seen that the latter model has $R^{2}$ values higher than those of the first-order kinetic along with all tested samples. This shows that the kinetic adsorption of PNP by phosphoric ACs derived from CRs suits better the pseudo-second order kinetic model rather than the pseudo-first order kinetic model. It is found that the average correlation coefficient of the second order is 0.990 and it is higher than that of the first order kinetic model $\sim 0.958$ (Table 5).

Table 5 . Kinetic parameters of PNP removal onto the prepared $A C s$ at $20^{\circ} \mathrm{C}$

\begin{tabular}{|c|c|c|c|c|c|c|c|c||}
\hline \multirow{3}{*}{ Samples } & \multicolumn{3}{|c|}{ First order kinetic } & \multicolumn{3}{c|}{ Second order kinetic } & \multicolumn{2}{c|}{ Intraparticle diffusion } \\
\cline { 2 - 10 } & $\begin{array}{c}\boldsymbol{q}_{\boldsymbol{e}} \\
(\mathrm{mg} / \mathrm{g})\end{array}$ & $\begin{array}{c}\boldsymbol{k}_{\boldsymbol{1}} \\
\left(\mathrm{min}^{-1}\right)\end{array}$ & $\boldsymbol{R}^{2}$ & $\begin{array}{c}\boldsymbol{q}_{\boldsymbol{e}} \\
(\mathrm{mg} / \mathrm{g})\end{array}$ & $\begin{array}{c}\boldsymbol{k}_{\boldsymbol{2}} \\
(\mathrm{g} / \mathrm{mg} \mathrm{min})\end{array}$ & $\boldsymbol{R}^{2}$ & $\begin{array}{c}\boldsymbol{k}_{\boldsymbol{d}} \\
\left(\mathrm{mg} / \mathrm{min}^{0.5}\right)\end{array}$ & $C_{i}$ \\
\hline $\mathbf{A C 4 0}$ & 15.1 & $3.6 \times 10^{-3}$ & 0.957 & 56.2 & $3.2 \times 10^{-4}$ & 0.999 & 4.4 & 18.5 \\
\hline $\mathbf{A C 4 5}$ & 42.6 & 0.011 & 0.965 & 62.9 & $2.5 \times 10^{-4}$ & 0.982 & 5.1 & 20 \\
\hline AC50 & 35 & $7.2 \times 10^{-3}$ & 0.953 & 65.4 & $2.3 \times 10^{-4}$ & 0.991 & 3.9 & 30.1 \\
\hline
\end{tabular}

Experimental kinetic data were further processed for testing the role of diffusion (as a rate-controlling step) in the adsorption process by an intraparticle diffusion model (Morris and Weber 1963). The uptake of PNP at time $t(\mathrm{~min})$ is proportional to the square root of contact time during the course of adsorption as follows:

$$
q_{t}=k_{d} \sqrt{t}+C_{i}
$$

where $k_{d}$ is the rate constant for intraparticle diffusion $\left(\mathrm{mg} / \mathrm{g} \mathrm{min}^{0.5}\right)$ calculated from the slope of the linear portion of $q_{t}-t^{0.5}$ plot; $t^{0.5}$ is the square root of the time; $C_{i}$ is the intercept at stage $I$; the value of $C_{i}$ is related to the thickness of a boundary layer. The larger the intercept $\left(C_{i}\right)$, the greater is the boundary layer effect. The calculated $k_{d}$ coefficient values are also listed in Table 5. The plots of $\mathrm{q}_{\mathrm{t}}$ versus $\mathrm{t}^{0.5}$ are shown in Figure 7. These plots show two stages of adsorption with deviation of a straight line from the origin that may be because of the difference in the rate of mass transfer between initial and final stages of adsorption. The initial linear portion refers to the boundary layer diffusion (film diffusion) and the latter portion due to the intraparticle diffusion during accessible micropores on the adsorbents with a very slow diffusion rate $\left(k_{d}=3.9-5.1 \mathrm{mg} / \mathrm{g} \mathrm{min}{ }^{0.5}\right)$. The same result was reported by (Ahmaruzzaman and Gayatri 2010). It can be observed that the value of $k_{d}$ for an AC45 sample is higher than those of two samples, whereas the value of intercept $C_{i}$, increases directly with the activation temperature, i.e. from 18.5 for AC40 to 30.1 for AC50. These results show a substantial effect of the activation temperature on both the adsorption mechanism of PNP and adsorption capacity.

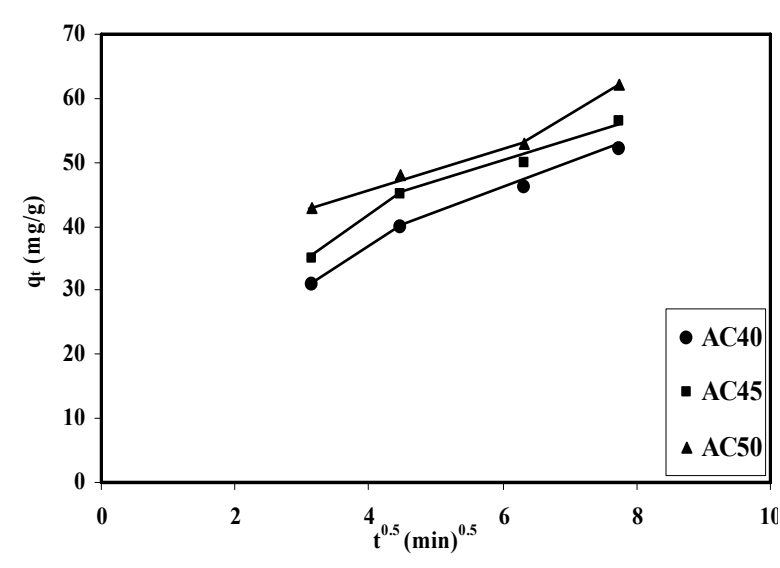

Fig. 7. Plots of intraparticle diffusion for kinetic removal of PNP onto the prepared ACs

\subsection{Thermodynamic measurements for PNP adsorption}

To study the effect of the temperature on adsorption of PNP by ACs, three temperatures were employed in the range of $20-60^{\circ} \mathrm{C}$. The thermodynamic parameters that are to be considered in estimating the process are: enthalpy of adsorption $\left(\Delta \mathrm{H}^{\mathrm{o}}\right)$, free energy change $\left(\Delta \mathrm{G}^{\mathrm{o}}\right)$, and entropy change $\left(\Delta \mathrm{S}^{\circ}\right)$ due to transfer of a unit mole of solute from solution on the solid-liquid interface (Fonseca and Airoldi 2001). The positive value of $\Delta \mathrm{H}^{\circ}$ indicates the endothermic process, and the negative value indicates the exothermic process. Parameter $\Delta S^{0}$ is used to identify spontaneity in the adsorption process. The values of $\Delta \mathrm{H}^{\circ}$ and $\Delta \mathrm{S}^{\circ}$ are evaluated using Van't Hoff equation as follows:

$$
\ln K_{L}=\frac{\Delta S^{\circ}}{R}-\frac{\Delta H^{\circ}}{2.303 R T}
$$


where $K_{L}$ is Langmuir constant $\mathrm{L} / \mathrm{g} ; T$, and $R$ are temperature and universal gas constant, respectively. $\Delta \mathrm{H}^{\mathrm{o}}$ and $\Delta \mathrm{S}^{\mathrm{o}}$ values are obtained from the slope and intercept of the plot of $\ln K_{L}$ versus $1 / \mathrm{T}\left(\mathrm{K}^{-1}\right)$ and presented in Table 4. It can be seen that the values of $\Delta \mathrm{G}^{\mathrm{o}}$ are negative; confirming that the adsorption of PNP along all carbons is spontaneous and thermodynamically favorable. The more negative values of $\Delta G^{0}$ imply that a greater driving force is required for the adsorption process. The higher adsorption capacity, the more negative values of $\Delta \mathrm{G}^{\circ}$ $(18.1-24.3 \mathrm{~kJ} / \mathrm{mol})$ are obtained. The positive value of $\Delta \mathrm{H}^{\mathrm{o}}$ shows the endothermic nature of adsorptions process, besides, it corresponds to chemisorption when it becomes higher than $40 \mathrm{~kJ} / \mathrm{mol}$. In the study, the calculated value of $\Delta \mathrm{H}^{\circ}$ is positive and lower than $40 \mathrm{~kJ} / \mathrm{mol}$ (i.e. adsorption of PNP occurred mainly by a physisorption process). The positive value of $\Delta \mathrm{S}^{\mathrm{o}}$ indicated also greater stability of an adsorption process with no structural changes at the solid-liquid interface. Similar results were obtained by adsorption of PNP by acid activated jute stick char $\left(\mathrm{H}_{3} \mathrm{PO}_{4}\right.$ acid in $1: 1 \mathrm{w} / \mathrm{w}$ at $110^{\circ} \mathrm{C}$ for $2 \mathrm{~h}$ and then at the raised temperature to $500^{\circ} \mathrm{C}$ for $4 \mathrm{~h}$ ) (Ahmaruzzaman and Gayatri 2010).

\section{Conclusions}

In the present work the biomass waste of common reeds (CR, or phragmites australis) was used as precursor for activated carbon (AC) production. The activation process was performed using $50 \mathrm{v} / \mathrm{v} \%$ of phosphoric acid at different temperatures (400$500^{\circ} \mathrm{C}$ ). The results showed that varying of the activation temperature from 400 to $500^{\circ} \mathrm{C}$ had a significant influence on textural and adsorptive properties of AC. The AC quality was evaluated in terms of the $\mathrm{N}_{2}$ adsorption, reflecting the surface area and adsorption of PNP as a model pollutant. Sample AC45 prepared by chemical activation of CR with 50 $\mathrm{v} / \mathrm{v} \% \mathrm{H}_{3} \mathrm{PO}_{4}$ at $450^{\circ} \mathrm{C}$ exhibited good microporosity texture $\left(\mathrm{S}_{\mathrm{mic}}=280 \mathrm{~m}^{2} / \mathrm{g}\right.$, and $\left.\mathrm{S}_{\mathrm{mic}} / \mathrm{S}_{\mathrm{t}}{ }^{\alpha}=86.2 \%\right)$ involved in the adsorption process of PNP. Under our experimental conditions the maximum adsorption capacity of these carbons was obtained at $40^{\circ} \mathrm{C}$ as follows: $\mathrm{q}_{\mathrm{m}}=153.8 \mathrm{mg} / \mathrm{g}$ for AC40, $227.3 \mathrm{mg} / \mathrm{g}$ for AC45 and $164 \mathrm{mg} / \mathrm{g}$ for AC50, respectively. The adsorption of PNP onto the investigated adsorbents is described by an isotherm of type I, and it is fully verified by Langmuir isotherm. The kinetics of this adsorbate was found to follow a pseudo-second order rate equation. Therefore, it can be concluded that the phosphoric acid-activation of CRs develops good adsorbing activated carbon with well-established porosity. This is revealed by an increased adsorbed amount of PNP with the augmented total surface area and microporosity. Finally, the use of CRs for the production of the ACs is very important from the view point of economic aspects, because they are cheap, widely available, and renewable sources, producing an effective adsorbent for removal of organic pollutants from wastewater.

\section{References}

Abdullah, I. D., Girgis, B.S., Tmerek, Y.M., Badawy, E. H., (2010), Potential of activated carbon derived from local common reed in the refining of raw cane sugar, Carbon letters, 11, 192-200.

Ahmadroup, A., Do D.D., (1997), The preparation of activated carbon from Macadamia nutshell by chemical activation, Carbon, 35, 1723-1732. http://dx.doi.org/10.1016/S0008-6223(97)00127-9

Ahmaruzzaman, M., Gayatri, S.L., (2010), Batch adsorption of 4-nitrophenol by acid activated jute stick char: Equilibrium, kinetic, thermodynamic studies, Chemical Engineering Journal, 158, 173-180. http://dx.doi.org/10.1016/j.cej.2009.12.027

Anirudhan, T., Sreekumari, S., Bringle, C., (2009), Removal of phenols from water and petroleum industry refinery effluents by activated carbon obtained from coconut coir pith, Adsorption, 15 (5-6), 439-451. http://dx.doi.org/10.1007/s10450-009-9193-6

Aravindhan, R., Rao, R. J., Nair, B.U., (2009), Preparation and characterization of activated carbon from marine macro-algal biomass, J. Hazard. Mater., 162, 688694. http://dx.doi.org/10.1016/j.jhazmat.2008.05.083

Attia, A.A., Girgis, B.S., Khedr, S.A., (2003), Capacity of activated carbon derived from pistachio shells by $\mathrm{H} 3 \mathrm{PO} 4$ in the removal of dyes and phenols, J. Chem. Technol. Biotechnol., 78, 611-619. http://dx.doi.org/10.1002/jctb.743

Ayranci, E., and Duman, O., (2005), Adsorption behaviors of some phenolic compounds onto high specific area activated carbon cloth, J. Hazard. Materials B, 124, 125-132. http://dx.doi.org/10.1016/j.jhazmat.2005.04.020

Bansal, R.C., Goyal, M., (2005), In: Activated Carbon Adsorption, Taylor and Francis, CRC Press, Boca Raton, New York.

Boehm, H.P., (1994), Some aspects of the surface chemistry of carbon blacks and other carbons, Carbon, 32, 759-766. http://dx.doi.org/10.1016/0008-6223(94)90031-0

Brunauer, S., Emmet, P.H., Teller, E., (1938), Adsorption of gases in multi-molecular layers. J. Am. Chem. Soc., 60, 309-319. http://dx.doi.org/10.1021/ja01269a023

Chandra, T.C., Mirna, M.M., Sudaryanto, Y., Ismadji, S., (2007), Adsorption of basic dye onto activated carbon prepared from durian shell: Studies of adsorption equilibrium and kinetics, Chem. Eng. Journal, 127, 121-29. http://dx.doi.org/10.1016/j.cej.2006.09.011

Chang, Y., Lv, X., Zha, F., Wang, Y., Lei, Z., (2009), Sorption of $\mathrm{p}$-nitrophenol by anion-cation modified palygorskite, J. Hazardous Materials, 168, 826-831. http://dx.doi.org/10.1016/j.jhazmat.2009.02.105

Chen, S., Zhang, J., Zhang, C., Yue, Q., Li, C., (2010), Equilibrium and kinetic studies of methyl orange and methyl violet adsorption on activated carbon derived from phragmites australis, Desalination, 252, 149-156. http://dx.doi.org/10.1016/j.desal.2009.10.010

Dabrowski, A., Podkoscielny, P., Hubicki, Z., Barczak, M., (2005), Adsorption of phenolic compounds by activated carbon-a critical review, Chemosphere, 58, 1049-1070.

Daifullah, A.A.M., Girgis, B.S., (1998). Removal of some substituted phenols by activated carbon obtained from 
agricultural waste, Water Research, 32 (4), 1169-1177. http://dx.doi.org/10.1016/S0043-1354(97)00310-2

Derbyshire, F., Jagtoyen, M., Andrews, R., Rao, A., Martin-Gullon, I., Grulke, E., (2001), Carbon materials in environmental applications, Radovic, L.R., Editor, Chemistry and Physics of Carbon, Marcel Dekker, New York, Vol. 27 ; p. 1-66.

Derylo-Marczewska, A., Goworek, J., Swiatkowski, A., Buczek, B., (2004), Influence of differences in porous structure within granules of activated carbon on adsorption of aromatics from aqueous solutions, Carbon, 42, 301-306. http://dx.doi.org/10.1016/j.carbon.2003.10.031

Devarly, P., Kartika, Y., Indraswati, N. Ismadji, S., (2008), Activated carbon from jackfruit peel waste by H3PO4 chemical activation: Pore structure and surface chemistry characterization, Chem. Eng. Journal, 140, 3242. http://dx.doi.org/10.1016/j.cej.2007.08.032

Diao, Y., Walawender, W.P., Fan, L.T., (2001), Activated carbons prepared from phosphoric acid activation of grain sorghum, Bioresource Technol., 81, 45-52. http://dx.doi.org/10.1016/S0960-8524(01)00100-6

El-Hendawy, A. N. A., Samra, S.E., Girgis, B.S., (2001), Adsorption characteristics of activated carbons obtained from corncobs, Colloid Surface A: Physicochem. Eng. Aspects, 180, 209-217. http://dx.doi.org/10.1016/S0927-7757(00)00682-8

Fan, M., Marshall, W., Daugaard, D., Brown, R.C., (2004), Steam activation of chars produced from oat hulls and cornstover, Bioresource Technol., 93, 103-117. http://dx.doi.org/10.1016/j.biortech.2003.08.016

Fathy, N.A., Girgis, B.S., Khalil, L.B., Farah, J.Y., (2010), Utilization of cotton stalks-biomass waste in the production of carbon adsorbents by $\mathrm{KOH}$ activation for removal of dye-contaminated water, Carbon Letters, 11(3), 224-234. http://dx.doi.org/10.5714/CL.2010.11.3.224

Finqueneisel, G., Zimnya, T., Albiniakb, A., Siemieniewskab, T., Vogt, D., Webera, J.V., (1998), Cheap adsorbent. Part 1: active cokes from lignites and improvement of their adsorptive properties by mild oxidation, Fuel, 77 (6), 549-556. http://dx.doi.org/10.1016/S0016-2361(97)00249-4

Fonseca, M.G., Airoldi, C., (2001), Thermodynamics data of interaction of copper nitrate with native and modified chrysotile fibers in aqueous solution, J. Colloid Interface Sci., $240, \quad 229$-236. http://dx.doi.org/10.1006/jcis.2001.7581

Frank, E., (2002), Paracetamol: a curriculum resource, Cambridge: Royal Society of Chemistry, ISBN 0-85404375-6.

Giles, C. H., Trivedi, A. S., (1969), A rapid method of determination of specific surface of solids by dye adsorption, Chem. Ind., 1426-1427.

Girgis, B.S., Attia. A.A., Fathy, N.A., (2007), Modification in adsorption characteristics of activated carbon produced by H3PO4 under flowing gases, Colloids and Surfaces A: Physicochem. Eng. Aspects, 299, 79-87. http://dx.doi.org/10.1016/j.colsurfa.2006.11.024

Girgis, B.S., El- Hendawy, A.A., (2002), Porosity development in activated carbon obtained from date pits under chemical activation with phosphoric acid, Micropore Mesop. Mat., 52, 105-117. http://dx.doi.org/10.1016/S13871811(01)00481-4

Girgis, B.S., Ishak, M.F. (1999), Activated carbon from cotton stalks by impregnation with phosphoric acid, $\begin{array}{llll}\text { Materials } & \text { Letters, } & 39, & 107-117 .\end{array}$ http://dx.doi.org/10.1016/S0167-577X(98)00225-0

Girgis, B.S., Yunis S.S., Soliman A.M., (2002), Characteristics of activated carbon from peanut hulls in relation to conditions of preparation, Materials Letters, 57, $164 \quad-\quad 172 . \quad \mathrm{http} / / / \mathrm{dx}$. doi.org/10.1016/S0167$577 \mathrm{X}(02) 00724-3$

Goyal, M., (2004), Adsorption of p-nitrophenol by surface modified carbons from aqueous solution, Carbon Science, 5 (2), 55-61.

Guo, Y., Rockstraw, D.A., (2007), Activated carbons prepared from rice hull by one-step phosphoric acid activation, Micropore Mesop. Mater., 100, 12-19. http://dx.doi.org/10.1016/j.micromeso.2006.10.006

Hashem, M.A., (2007), Adsorption of lead ions from aqueous solution by okra wastes, Int. J. Physical Sci., 2, 178-184.

HO, Y.S., McKay, G., (1999), Pseudo-second order model for sorption processes, Proc. Biochem., 34, 45104565 .

Horsfall, M. Jr., Spiff, A.I., (2005), Effects of temperature on the sorption of $\mathrm{Pb} 2+$ and $\mathrm{Cd} 2+$ from aqueous solution by Caladium bicolor (Wild Cocoyam) biomass, Electronic J. Biotechnol., 8, 162-169. http://dx.doi.org/10.2225/vol8-issue2-fulltext-4

Jagtoyen, M., Derbyshire, F., (1998), Activated carbons from yellow poplar and white oak by H3PO4 activation, Carbon, 36, $108 \quad-1097$. http://dx.doi.org/10.1016/S0008-6223(98)00082-7

Jagtoyen, M., Thwaites, M., Stencel, B., Mc Enaney, B., Derbyshire F., (1992), Adsorbent carbon synthesis from coals by phosphoric acid activation, Carbon, 30, 10891096. http://dx.doi.org/10.1016/0008-6223(92)90140-R

Juang, R.-S., Shiau, J.-Y., Shao, J.-H., (1999), Effect of temperature on equilibrium adsorption of phenols onto nonionic polymeric resins, Sep. Sci. Technol., 34 (9), 18191831. http://dx.doi.org/10.1081/SS-100100740

Juang, R.S., Wu, F.C., Tseng, R.L., (1996), Adsorption isotherms of phenolic compounds from aqueous solutions onto activated carbon fibers, J. Chem. Eng. Data, 41, 487-495. http://dx.doi.org/10.1021/je950238g

Kufel, I., Kufel, L., (1980), Chemical composition of reed (Phragmites australis TRin.ex Steudel) in relation to the substratum, Bull. Acad. Polon. Sci., 28, 563-568.

Lagergren, S., (1980), Zur theorie der sogenannten adsorption gelöster stoffe, Kungliga Svenska Vetenskapskademines, 24, Handlingar, pp. 1-39.

Laine, J., Calafat, A., Labady, M., (1989), Preparation and characteristics of activated carbons from coconut shell impregnated with phosphoric acid, Carbon, 27(2), 191-195. http://dx.doi.org/10.1016/0008-6223(89)90123-1

Li, L., Quinlivan, P.A., Knappe, D.R.U. (2002), Effects of activated carbon surface chemistry and pore structure on the adsorption of organic contaminants from aqueous solution, Carbon, 40, 2085-2100. http://dx.doi.org/10.1016/S0008-6223(02)00069-6

Lua, A.C., Ting, Y., (2004), Effect of activation temperature on the textural and chemical properties of potassium hydroxide activated carbon prepared from pistachio-nut shell, J. Colloid and Interface Sci., 274, 594 606. http://dx.doi.org/10.1016/j.jcis.2003.10.001

Lua, A.C., Yang, T., Guo, J., (2004), Effects of pyrolysis conditions on the properties of activated carbons prepared from pistachio-nut shells, J. Anal. Appl. Pyrol., 72, 279-87. http://dx.doi.org/10.1016/j.jaap.2004.08.001

Molina-Sabio, M., Rodriguez-Reinoso, F., Caturla, F., Selles, M. J., (1995), Porosity in granular carbons activated with phosphoric acid, Carbon, 33 (8): 1105 1111. http://dx.doi.org/10.1016/0008-6223(95)00059-M

Molina-Sabio, M., Rodriguez-Reinoso, F., Caturla, F., Selles, M.J., (1996), Development of porosity in combined phosphoric acid - carbon dioxide activation, 
Carbon, 34, 457 - 462. http://dx.doi.org/10.1016/00086223(95)00209-X

Moreno-Castilla, C., (2004), Adsorption of organic molecules from aqueous solutions on carbon materials, Carbon, 42 ,

83-94. http://dx.doi.org/10.1016/j.carbon.2003.09.022

Morris, J., Weber, W.J., (1963), Kinetics of adsorption on carbon from solution, J. Saint Eng. Div. Am. Soc. Civil. Eng., 89, 31- 39.

Mourao, P.A.M., Carrott, P.J.M., Ribeiro-Carrott, M.M.L., (2006), Application of different equations to adsorption isotherms of phenolic compounds on activated carbons prepared from cork, Carbon, 44, 2422-2429. http://dx.doi.org/10.1016/j.carbon.2006.05.015

Namane, A., Mekarzia, A., Benrachedi, K., Belhaneche-Bensemra, N., Hellal, A., (2005), Determination of the adsorption capacity of activated carbon made from coffee grounds by chemical activation with $\mathrm{ZnCl} 2 \neg$ and H3PO4, J. hazard. Mater., B119, 189-194. http://dx.doi.org/10.1016/j.jhazmat.2004.12.006

Nour, S., Haghseresh, F., Maxlu, G.Q., (2002), Comparison of adsorption capacity of $\mathrm{p}$-cresol and $\mathrm{p}$ nitrophenol by activated carbon in single and double solute, Adsorption, 8 , $215-223$ http://dx.doi.org/10.1023/A:1021260501001

Patrick, J.W., (1995), Porosity in Carbons: Characterization and Applications, Edward Arnold, London.

Philip, C.A., Girgis, B.S., (1996), Adsorption characteristics of microporous carbons from apricot stones activated by phosphoric acid, J. Chem. Technol. Biotechnol., 67 , 248-254.

http://dx.doi.org/10.1002/(SICI)1097-

4660(199611)67:3<248::AID-JCTB557>3.0.CO;2-1

Pura, S., Atun, G., (2005), Enhancement of nitrophenol adsorption in the presence of anionic surfactant and the effect of the substituent position, Colloids and Interfaces A: Physicochem. Eng. Aspects, 253, 137-144 http://dx.doi.org/10.1016/j.colsurfa.2004.11.004

Puziy, A.M., Poddubnaya, O.I., Martínez-Alonso, A., Castro-Muniz, A., Suárez-Garcia, F., Tascón, J.M.D., (2007), Oxygen and phosphorous enriched carbons from lignocellulosic material, Carbon, 45, 1941-1950. http://dx.doi.org/10.1016/j.carbon.2007.06.014

Puziy, A.M., Poddubnaya, O.I., Martínez-Alonso, A., Suárez-Garcia, F., Tascón, J.M.D., (2002), Synthetic carbons activated with phosphoric acid I. Surface chemistry and Ion bonding properties, Carbon, 40, 1493-1505. http://dx.doi.org/10.1016/S0008-6223(01)00317-7
Radhika, M., Palanivelu, K., (2006), Adsorptive removal of chlorophenols from aqueous solution by low cost adsorbent-Kinetics and isotherm analysis, J. hazard. Mater., B138, 116-124. http://dx.doi.org/10.1016/j.jhazmat.2006.05.045

Radovic, L.R., Moreno-Castilla, C., Rivera -Utrilla, J., (2001), Carbon materials as adsorbents in aqueous solutions, In: Radovic LR, Editor, Chemistry and Physics of Carbon, Marcel Dekker, Vol. 27, p. 228-405.

Rodriguez-Reinoso, F., Molina-Sabio, M., (1992), Activated carbons from lignocellulosic materials by chemical and /or physical activation: an overview, Carbon, 30 (7), 1111- 1118. http://dx.doi.org/10.1016/00086223(92)90143-K

Rouquerol, F., Rouquerol J., Sing K.S.W., (1999), Adsorption by Powders and Porous Solids. In: Principles, Methodology and Applications, Academic Press, San Diego, CA, chap 9.

Selles-Perez, M.J., Martin-Martinez, T.M., (1991), Application of and $\mathrm{n}$ plots to N2 - adsorption isotherms of activated carbons, J. Chem. Soc. Faraday Trans., 87, 1237-1243. http://dx.doi.org/10.1039/ft9918701237

Southichak, B., Nakano, K., Nomura, M., Chiba, N., Nishimura, O., (2006), Phragmites australis: A novel biosorbent for the removal of heavy metals from aqueous solution, Water Research, 40, 2295-2302. http://dx.doi.org/10.1016/j.watres.2006.04.027

Suarez-Garcia, F., Martinez-Alonso, F., Tascon, J.M.D., (2002), Pyrolysis of apple pulp: chemical activation wit phosphoric acid, J. Anal. Appl. Pyrolysis, 63, 283-301. http://dx.doi.org/10.1016/S0165-2370(01)00160-7

Tang, D., Zheng, Z., Lin, K., Luan, J., Zhang, J., (2010), Adsorption of p-nitrophenol from aqueous solutions onto activated carbon fiber, J. Hazard. Mater., 143, 49-56. http://dx.doi.org/10.1016/j.jhazmat.2006.08.066

US Environmental Protection Agency (1980), Nitrophenols, Ambient Water Quality Criteria, USEPA, Washington, DC.

Villaescusa, I., Fiol, N., Martinez, M., Miralles, N., Poch, J., Serarols, J., (2004), Removal of copper and nickel ions from aqueous solutions by grape stalks wastes, Water Research, 38, 992-1002. http://dx.doi.org/10.1016/j.watres.2003.10.040

Zhang, T., Walawender, W.P., Fan, L., Fan, M., Daugaard, D., Brown, R.C., (2004), Preparation of activated carbon from forest and agricultural residues through $\mathrm{CO} 2$ activation, Chem. Eng. Journal, 105, 53-59. http://dx.doi.org/10.1016/j.cej.2004.06.011 